\title{
Comparative effects of Saccharomyces cerevisiae and Aspergillus oryzae on rumen fermentations
}

\author{
F Mathieu 1,2, JP Jouany 1, G Bertin 2, J Senaud 3 \\ 1 INRA, Station de Recherches sur la Nutrition des Herbivores, CR de Clermont-Ferrand-Theix, \\ 63122 Saint-Genès-Champanelle, France; ${ }^{2}$ Santel-Groupe Agritek, 85 rue Anatole France, 92300 Levallois \\ Perret, France; ${ }^{3}$ Université Blaise Pascal, URA CNRS 144, Les cézeaux, 63177 Aubière Cédex, France
}

Saccharomyces cerevisiae (SC) and Aspergillus oryzae (AO) have both been proposed as biological feed additives to improve feed efficiency in ruminants. Scepticism about the efficiency of these products has been allayed by some recent trials which showed that they stimulated animal production in same conditions. Numerous basic studies on probiotics have also been undertaken over the last decade to understand their possible mode of action. The present study was carried out to compare the effect of the two main probiotics used in ruminant feeding on rumen fermentations.

Six adult sheep fitted with rumen cannulae and harbouring a B-type mixture of protozoa were used during 3 periods: they received no probiotics during the first period (control); 3 sheep received $S^{*}{ }^{*}\left(50 \mathrm{mg} \mathrm{DM}^{-1} \mathrm{~d}^{-1} ; 20.10^{9}\right.$ CFU. $\left.{ }^{-1}\right)$ and the 3 other sheeps received $A O$

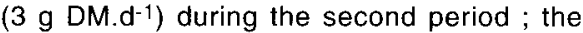
distribution of probiotics to the animals was reversed during the third period. Animals were fed a diet composed of barley (600 g.d-1), grass hay $\left(600 \mathrm{~g}^{-\mathrm{d}^{-1}}\right)$ and soybean meal (150 g. d $^{-1}$ ) given in two equal meals. Rumen contents were sampled at different time after the morning meal $(0,0.5,1,1.5,2,3,5,7$ hours).

\footnotetext{
${ }^{\star}$ Registrated as strain 1-1077 at Institut Pasteur, Paris
}

Neither of the 2 probiotics had a significant effect on the $\mathrm{pH}$ values after feeding. However the $\mathrm{pH}$ was always higher than 6.0 with both probiotics, while it remained under this value for 6 hours during the control period. $\mathrm{NH}_{3}-\mathrm{N}$ concentration was always higher in the rumen of animals receiving probiotics. The significant threshold $(p<0.05)$ was only reached during the first hour after feeding with SC. This could indicate that the degradation of rapidly digestible proteins was stimulated if we assume that $\mathrm{NH}_{3}$ capture by bacteria was not decreased by probiotics.

No significant effect of probiotics was observed on the concentration of total VFAs. A slight but non-significant decrease of the concentration of acetate and propionate were noted 2 hours after feeding and maintained for 5 hours. The significant threshold $(P<0.05)$ was reached 3 and 5 hours after feeding with acetate and from 2 until 5 hours with propionate. The $\mathrm{C}_{2} / \mathrm{C}_{3}$ ratio remained unchanged at all the sampling times and for the 3 test periods. No significant effect of probiotics was noted on butyrate, valerate and caproate concentration. From 3 until 7 hours after feeding an increase in branched VFA was observed which confirms the stimulating effect of probiotics on protein degradation. 